\title{
Association of volume estimation accuracy obtained using USS, CT and volume calculation formulae for different shaped objects
}

\author{
Kodikara SKYI ${ }^{1}$, Gamage DTK ${ }^{2}$, Abeysekara I ${ }^{3}$, Gamage LGM ${ }^{1}$, Ilayperuma I ${ }^{1}$ \\ ${ }^{\prime}$ Department of Anatomy, Faculty of Medicine, University of Ruhuna. \\ ${ }^{2}$ Teaching Hospital, Rathnapura. \\ ${ }^{3}$ National Dengue Control Unit, Colombo
}

Ultrasonography (USS) and computer-

tomography $(\mathrm{CT})$ are frequently

warranted for volume estimation of

internal organs. Volume estimation

accuracy is said to be influenced by the

shape of the object. The scanner utilizes

formula to calculate the volume of a specific shaped object. Therefore the volume estimation error described for non-globular objects may be related to the calculation formula used. The study aimed to evaluate the association of volume estimation error among USS, $\mathrm{CT}$ and volume estimation formula. Globular (Gb); elongated (IR) and near spherical (NGb) shaped hollow plastic objects were filled with water and subjected to USS and CT to obtain length, width, depth and estimated volume (EV). Manual volume calculation was performed using prolate (PV), ellipsoid (SV) and Lambert (LV) formulae. The actual volume (AV), EV and calculated volume was compared. The AV ranged from 10 to $445 \mathrm{ml}$. Mean EV of USS; $\mathrm{CT} ; \mathrm{SV} ; \mathrm{PV}$ and $\mathrm{LV}$ were $97.9 \mathrm{ml}$

\author{
$(\mathrm{r}=0.98 ; \mathrm{p}<0.001) ; 89.1 \mathrm{ml}$ \\ $(\mathrm{r}=0.97 ; \mathrm{p}<0.001) ; 97 \mathrm{ml}$ \\ $(\mathrm{r}=0.99 ; \mathrm{p}<0.001) ; 108.5 \mathrm{ml}$ \\ $(\mathrm{r}=0.97 ; \mathrm{p}<0.001)$ and $132.5 \mathrm{ml}$ \\ $(\mathrm{r}=0.99 ; \mathrm{p}<0.001)$ respectively. Volume \\ of all shapes were estimated with \\ highest and lowest accuracy using PV \\ (bias $=-0.7)$ and LV (bias $=+23.3$ ) \\ respectively. Regardless of the shape of \\ object, EV of PV and LV has shown the \\ highest $($ bias $=-0.7$; precession $=19.8$ ) \\ and lowest accuracy (bias $=21.8$; \\ precession=12.8) respectively. Among \\ all shapes, volume of $\mathrm{Gb}$ were \\ estimated with highest accuracy \\ irrespective of the method used: \\ (USS[bias $=-0.31$ ]; CT[bias $=-0.14]$; \\ $\mathrm{SV}$ [bias=-1.5]; PV[bias=-0.7]; \\ LV[bias=32.9]); volume of IR were \\ estimated with lowest \\ accuracy:(USS[bias $=-17.5]$; CT[bias $=-$ \\ 32.6]; SV[bias=-18.4]; $P V[$ bias $=-0.3$ ]; \\ $\mathrm{LV}[$ bias=11.4]).Shape of the object and \\ calculation formula used were shown to \\ have an impact on the volume \\ estimation accuracy.
}

